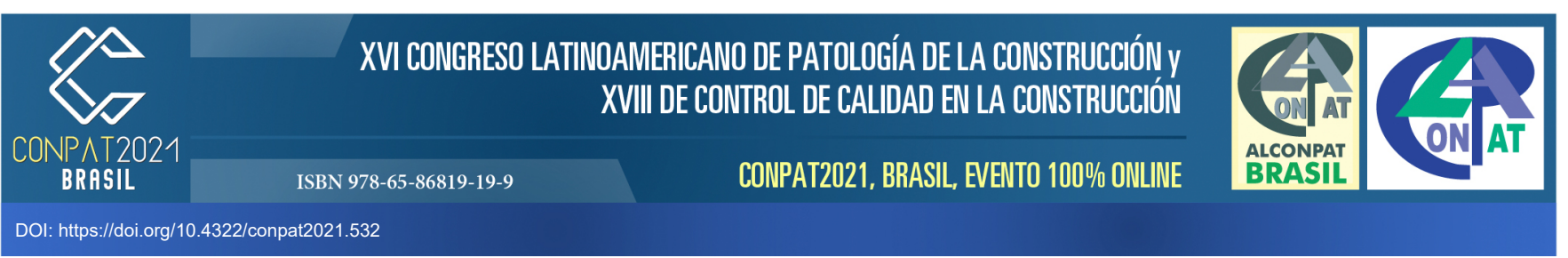

\title{
Recuperação de estrutura subaquática: Estudo de caso em Salvador/Ba
}

\author{
A. R. A. OMORE ${ }^{1 *}$, V. A. COELHO ${ }^{2}$, M. V. A. S. MENDES ${ }^{3}$, F. G. S. SILVA ${ }^{4}$ \\ *Autor de Contacto: abrahamrodolphe@gmail.com \\ ${ }^{1}$ PPEC, Escola Politécnica, Universidade Federal da Bahia, Salvador, Brasil \\ ${ }^{2}$ NUCCTEC, Curso Bacharelado em Engenharia Civil, Instituto Federal de Goiás, Goiânia, Brasil \\ ${ }^{3}$ Graduado em Engenharia Civil, Escola Politécnica, Universidade Federal da Bahia, Salvador, Brasil \\ ${ }^{4}$ DCE, Escola Politécnica, Universidade Federal da Bahia, Salvador, Brasil
}

\begin{abstract}
RESUMO
As estruturas de concreto localizadas em um ambiente marinho podem estar sujeitas a vários tipos de degradação. O concreto submerso no ambiente marinho é preparado para suportar uma série de agressões ao longo de seu ciclo de vida como a corrosão das armaduras e o ataque de cloretos presentes na água do mar. O objetivo do presente estudo consiste na recuperação dos blocos de concreto de fundação de um píer, com base na avaliação do estado de conservação de mais 20 anos. Dessa forma, foi possível coletar material e ilustrar a importância das técnicas a serem aplicadas, apresentando o passo a passo da execução de projeto de recuperação dos blocos submersos, com finalidade de prolongar a vida útil da estrutura.
\end{abstract}

Palavras-chave: Concreto submerso; Píer; Vida útil.

Underwater structure recovery: A case study in Salvador/BA. 


\begin{abstract}
Concrete structures located in a marine environment can be subject to various types of degradation. Submerged concrete in the marine environment is prepared to withstand a series of aggressions throughout its life cycle, such as reinforcement corrosion and the attack of chlorides present in sea water. The aim of this study is to recover the concrete foundation blocks of a pier, based on an assessment of the conservation status of over 20 years. Thus, it was possible to collect material and illustrate the importance of the techniques to be applied, presenting the step-by-step execution of a submerged block recovery project, in order to prolong the structure service life.
\end{abstract}

Keywords: Submerged concrete; Pier; Service life.

\title{
Recuperación de estructuras submarinas: estudio de caso em Salvador / Ba
}

\section{RESUMEN}

Las estructuras de hormigón ubicadas en un entorno marino pueden estar sujetas a varios tipos de degradación. El hormigón sumergido en el medio marino está preparado para soportar una serie de agresiones a lo largo de su ciclo de vida, como la corrosión de las armaduras y el ataque de los cloruros presentes en el agua de mar. El objetivo de este estudio es recuperar los bloques de cimentación de hormigón de un muelle, a partir de una evaluación del estado de conservación de más de 20 años. Así, fue posible recolectar material e ilustrar la importancia de las técnicas a aplicar, presentando el paso a paso de un proyecto de recuperación de bloques sumergidos, con el fin de prolongar la vida útil de la estructura.

Palabras clave: Hormigón sumergido; Muelle; Vida útil.

\section{INTRODUÇÃO}

Os ambientes marinhos apresentam elevada agressividade ao concreto armado, principalmente devido à combinação de cloretos e umidade. As estruturas encontradas nesses ambientes estão sujeitas a numerosos ataques (mecânicos, químicos, físicos e biológicos). A corrosão da armadura é também uma das principais causas da deterioração das estruturas de concreto armado, especialmente no ambiente marinho. A estrutura pode ser submetida a um ou mais ataques simultaneamente e o grau de agressividade varia conforme o fato do concreto estar completamente submerso em uma zona de maré ou fora d'água (LONG, 2013). 
A deterioração é o processo de alteração física e química de um material por elementos agressores, os agentes de deterioração. Esse processo tende a comprometer as estruturas e os materiais (SOUZA; RIPPER, 2009). Segundo Souza e Ripper (2009), ao estudar a vida útil das estruturas, há que se ter em vista o que é tecnicamente possível, considerando também a durabilidade dos materiais, das estruturas e a evolução constante dos processos de construção e de manutenção, bem como o aprimoramento dos programas.

Medidas de manutenção são as ações técnicas e econômicas que tentam elevar o nível de qualidade de um elemento de construção e/ou restaurar o nível de desempenho inicial. Essas ações são executadas para antecipar a falha dos elementos ou corrigir localmente os defeitos existentes, o que se denomina de manutenção proativa e reativa, respectivamente.

Um diagnóstico correto deve definir o problema, coletar os dados disponíveis, caracterizar as anomalias existentes e suas prováveis causas, avaliar o desempenho em serviço, verificar se as demandas dos usuários estão sendo cumpridas e, finalmente, definir as medidas corretivas, preventivas ou ações de monitoramento.

Em estruturas subaquáticas, concreto submerso é a denominação dada ao concreto que é aplicado na presença de água, como em estruturas de contenção ou em meio à lama bentonítica. A principal característica do concreto submerso é a maior coesão dos grãos, o que não permite sua dispersão no contato com a água, oferecendo maior resistência ao ataque químico (GOMES, 2016).

A revisão bibliográfica especifica do assunto refere-se as patologias de estruturas de concreto no ambiente subaquático, descrevendo as causas do dano. Além disso, propõe algumas técnicas de reparo que permitem que o trabalho permaneça em condições de manutenção. Nesse contexto, diante da necessidade de conhecer mais sobre estruturas de concreto subaquáticas no ambiente marinho, o desenvolvimento do presente trabalho apresenta estudo pioneiro relacionado à recuperação de blocos submersos de um píer localizado em Salvador/BA.

\section{Fatores de degradação do concreto em ambientes marinhos e subaquáticos}

O concreto é usado para a realização de um grande número de estruturas localizadas em locais marítimos. Para Mehta (1991), essas estruturas participam do desenvolvimento de infraestrutura e instalações de portos de pesca, lojas, terminais de contêineres, docas e cais para carregar e descarregar, píer. Essas estruturas estão expostas a vários tipos de configurações. Dependendo das variações no nível do mar, o concreto pode ser:

- Submerso ou subaquático continuamente (concreto localizado abaixo do nível do mar na maré baixa). Os concretos localizados nessa área raramente estão sujeitos à degradação significativa a concentração de oxigênio é baixa (comparada a atmosfera) e limita a reação de oxidação por falta de oxigênio para produzir corrosão. Também produz corrosão, mas a velocidade é menor (comparado a exposição atmosférica) devido à baixa concentração de $\mathrm{O}_{2}$. Embora a concentração de íons cloreto na área submersa exceda o limite necessário para iniciar a corrosão das armaduras, a disponibilidade e a difusão de oxigênio no concreto completamente saturado é muito lenta e causa apenas uma taxa de corrosão muito baixa.

- Alternadamente imerso e submerso ou subaquático conforme o nível do mar (áreas de maré determinados pelos níveis de maré alta e baixa). O concreto nessa área está repetidamente sujeito ao ciclo de secagem a seco. Uma forte concentração de íons cloreto, bem como uma quantidade suficiente de oxigênio, estão presentes nessa área, o que levará à corrosão das armaduras. A região representa o mais desfavorável para a vida da estrutura. Além das restrições citadas, a estrutura também pode estar sujeita a gelo e degelo.

- Continuamente fora da água. O concreto localizado nessa área pode estar sujeito a agressões leves. A diferença no nível de corrosão entre esta área e a alternadamente imersa/submersa encontra-se na presença de sal e umidade no concreto. O concreto na área continuamente 
fora da água, embora não esteja em contato direto com a água do mar, sofre a ação da neblina e do spray do mar. O concreto nesta área não sofre abrasão física devido à ação de onda.

\subsection{Agentes de degradação do concreto}

$\mathrm{O}$ concreto em um ambiente marinho pode ser submetido a várias reações químicas. A degradação pode ser causada por íons na água do mar, o que resulta em um ataque químico de origem externa ao concreto, além de também ser provocada por íons presentes nos constituintes do próprio concreto.

Os ambientes que possuem altas concentrações de $\mathrm{CO}_{2}$ comprometem a durabilidade das estruturas de concreto armado por causa da penetração dessa substância nos poros do concreto. Com a presença concomitante de hidróxido de cálcio, gás carbônico e água promove uma reação que produz carbonato de cálcio e reduz a alcalinidade do concreto (NEVILLE, 2016).

Segundo Neville (2016), a ação principal do ataque por cloretos é a corrosão do aço, pois somente a partir da corrosão da armadura inicia-se a degradação no concreto. A corrosão das armaduras é mais um sintoma do que uma causa de degradação do concreto, o que significa que certos processos enfraquecem o concreto, levando à corrosão. A penetração de cloretos e a carbonatação são os dois processos que podem alterar a proteção fornecida pelo concreto.

\subsubsection{Causas de corrosão}

No ambiente marinho, a penetração de cloretos é o principal fenômeno de corrosão de armaduras. Em um ambiente saturado, no caso de estruturas submersas, cloretos penetram na porosidade do concreto por um fenômeno de difusão. Quando a concentração de íons cloreto, na vizinhança do aço, excede um valor crítico estimado, há despassivação seguida da corrosão de armaduras. A taxa de corrosão, devido à penetração do cloreto na água do mar, depende da disponibilidade de oxigênio. Consequentemente, as armaduras do concreto na zona continuamente submersa mostram apenas uma baixa taxa de corrosão, apesar de uma grande quantidade de cloretos contidos na água do mar. Por outro lado, o concreto nas zonas de maré e de respingo está sujeito ao ciclo de molhagem e secagem, o que proporciona uma alta concentração de íons cloreto bem como uma quantidade suficiente de oxigênio, que é a condição mais favorável para corrosão de armaduras, ademais sabe-se que a temperatura aumenta a velocidade de corrosão significativamente.

\section{ESTUDO DE CASO}

O píer é uma estrutura construída à beira-mar e para dentro dele com a finalidade de permitir a atracação das embarcações e, também, o passeio público. A obra do referido estudo de caso é um píer a beira mar, situado na cidade de Salvador-BA, que foi construído há aproximadamente 20 anos (Figura 1). 

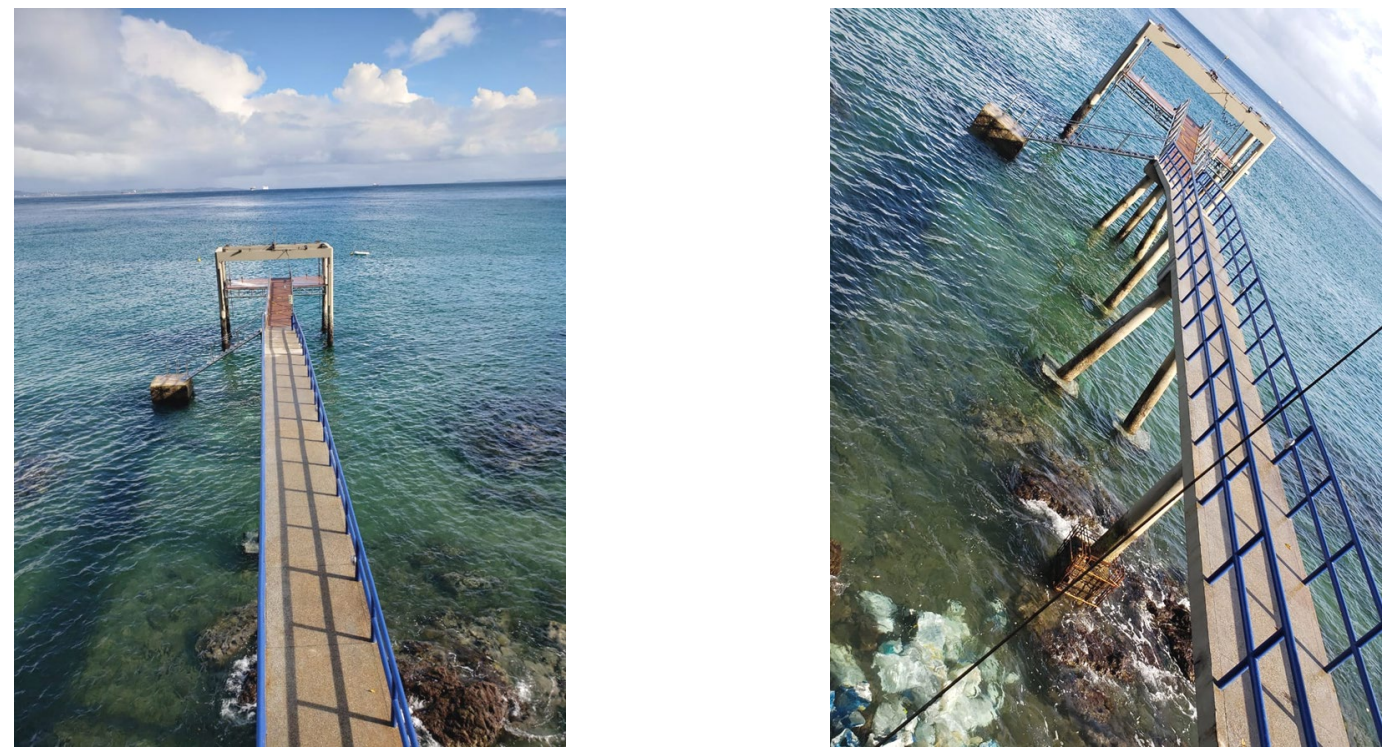

Figura 1- Vista do píer

O píer tem toda sua estrutura concebida em concreto armado aparente e é formado por uma ponte e um atracadouro. Na parte submersa, os blocos de concreto da ponte estão com a forma retangular, enquanto os blocos de pilares do atracadouro estão na forma cilíndrica. O píer tem $2 \mathrm{~m}$ de largura que adentra o mar numa extensão de $50 \mathrm{~m}$.

Foram observados problemas na estrutura do píer 11 anos após sua construção. Foi realizado o levantamento das anomalias estruturais e, posteriormente, apresentado um relatório técnico com descrição dos problemas encontrados, no qual foram relatados as técnicas e os materiais para a recuperação do píer, além de apresentar o desenho com as dimensões dos elementos estruturais da estrutura.

No ano de 2012, a parte emersa do píer foi recuperada. Em maio de 2017, a estrutura foi vistoriada, momento em que se observou fissuras e rachaduras decorrentes de corrosão de armaduras. Em julho daquele ano, recomendou-se não utilizar o pórtico espacial no fim do píer como atracadouro ou para acostamento de embarcações marítimas até maiores investigações das consequências das anomalias observadas.

Em 2018 foi feita uma vistoria (Figura 2), impressionando com o avanço da deterioração da corrosão em toda a estrutura.
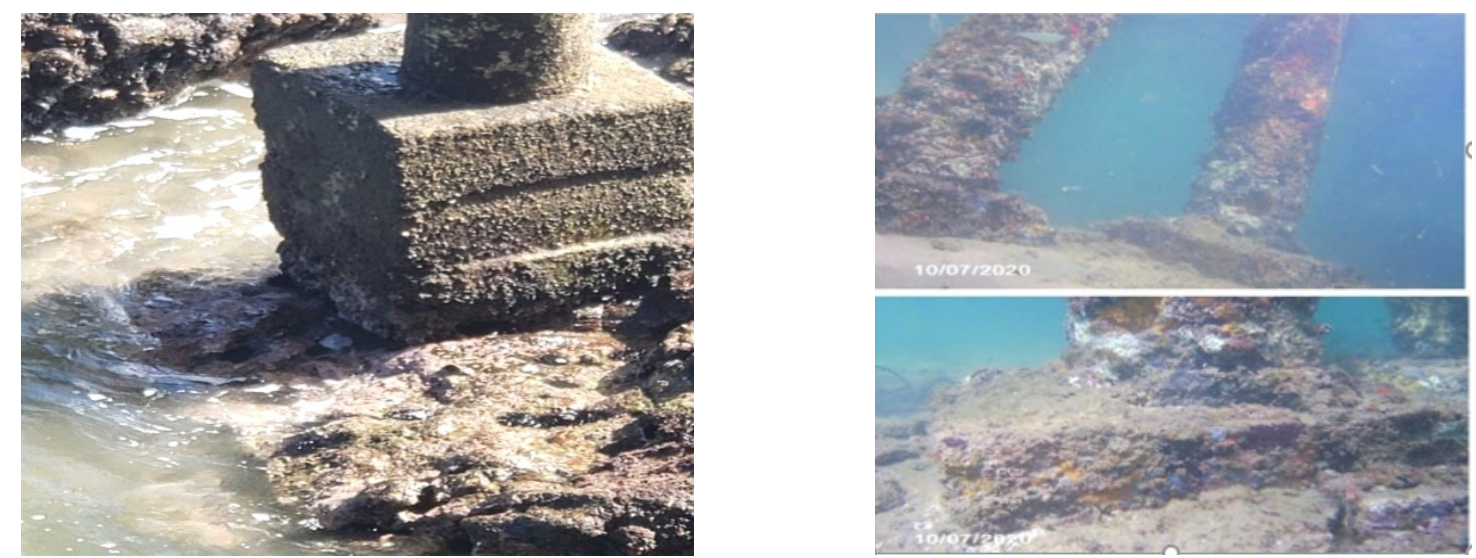

Figura 2: Corrosão avançada no bloco do atracadouro do píer. 


\section{Plano de recuperação dos blocos}

Para Allen, Edwards e Shaw (1994), antes de realizar uma operação de reparo, muitas vezes é necessário limpar a área para permitir uma inspeção detalhada. Somente depois da avaliação da extensão do dano usando mergulhadores ou veículos operados remotamente para fotografar a área, pode ser preparado um programa de reparo. Assim, o processo de recuperação foi feito em quatro etapas:

Etapa 1: A primeira etapa do reparo foi remover todo o concreto fissurado ou rachado. Em alguns casos, também pode ser necessário cortar a armadura distorcida.

Dependendo da profundidade da área danificada e da idade da estrutura, podem existir vários níveis de incrustação marinha. É necessário remover qualquer camada na superfície para ser capaz de definir a extensão do dano e, também, garantir uma boa ligação entre os materiais existentes e os de reparo. Os procedimentos de limpeza e preparo do substrato são tão importantes, que alguns autores (ACI COMMITTEE 1998) tratam como 50\% de importância em todo o processo de recuperação e reforço da estrutura. De acordo com Helene (1992), a limpeza do substrato é um tratamento prévio da superfície dos componentes estruturais. Esse tipo de processo ajuda a remover fungos, o concreto afetado e outros microrganismos presentes na superfície do bloco submerso (Figura 4).

As técnicas de limpeza utilizadas consistem em: escovação manual; lixamento manual para preparo da superfície com lixa d'água para concreto; jateamento de ar utilizado para expulsão de resíduos naturais ou resultantes de outras preparações de superfície (plataformas de trabalho podem ser necessárias); lixa de ferro para aço, com a utilização do disco de lixa acoplado a uma lixadeira eletromecânica provida de um protetor; jato de areia seco; disco de corte; martelete pneumático com compressor ou eletromecânico; escarificação; raspador; mangote, dentre outros.

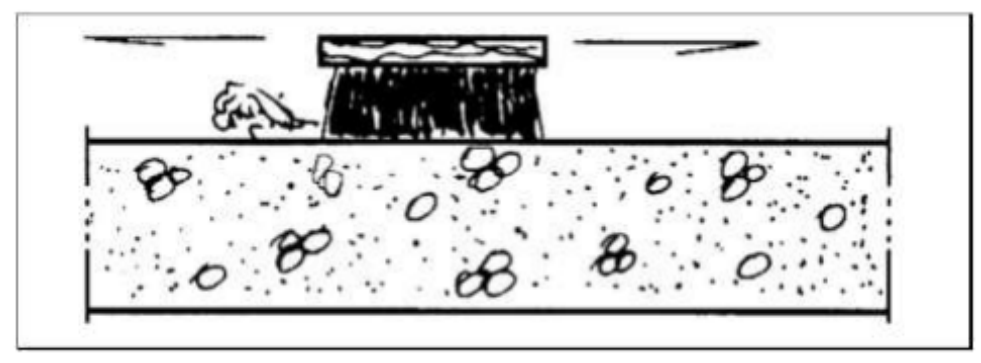

Figura 3: Limpeza com raspador

Etapa 2: Em seguida, é necessário realizar o apicoamento manual com o objetivo final de deixar a superfície bastante áspera e adequada para receber materiais de proteção e de recuperação ou reforço, tais como argamassas ou concreto projetado (Figura 5).

Etapa 3: A armadura empregada foi cortada e dobrada conforme o projeto no canteiro da obra da empresa responsável pela execução. Para garantir uma maior proteção das armaduras, foi aplicado um revestimento epóxi de qualidade, prevenindo contra oxidação, corrosão, ferrugem e, também, ataques químicos. Foi garantida a retirada da camada com espessura de $45 \mathrm{~cm}$ de areia abaixo do bloco existente para executar o encamisamento do bloco. E depois do encamisamento, foi feito o nivelamento com solo, considerando que o ideal é sempre deixar chegar à rocha, o que dá mais durabilidade à estrutura (Figura 6). 
Etapa 4: O projeto de produção de forma, bem como os procedimentos, são produtos naturalmente decorrentes do planejamento e da definição do processo de execução. Ele foi concebido pela própria empresa responsável pelo reparo. Quanto à colocação das formas, todo o cuidado deve ser tomado, de modo a garantir o perfeito posicionamento da armadura no elemento final a ser concretado. Os dois problemas fundamentais a serem evitados nesses procedimentos de colocação da armadura e forma são a falta do cobrimento de concreto especificado e o posicionamento incorreto da armadura. Para vedar a parte inferior da forma, utiliza-se a mistura de barro e cimento para impedir a perda do concreto no processo de concretagem (Figura 7).

Etapa 5: Nesse processo, (Figura 8) as formas recebem a brita e as ferragens. Então um grande agregado grosso de tamanho único, normalmente não inferior a $40 \mathrm{~mm}$, é colocado na forma preparada. No preenchimento da forma com brita, é importante a preocupação em relação ao empacotamento granulométrico (que auxilia na maior coesão dos grãos do concreto, evitando a sua dispersão no contato com a água.

Etapa 6: Na sequência, é injetada, por pressão ou por gravidade, a pasta (cimento puro e água) ou uma nata (cimento e areia) nos espaços da brita.

Nesse procedimento, o traço da nata incluiu: cimento (2 sacos de $50 \mathrm{~kg}$ ), areia (6 latas) e água (60L). Considerando a variação da água dependente de sua presença na areia, foi utilizado o cimento CP II-F-40 RS. (Figura 9).

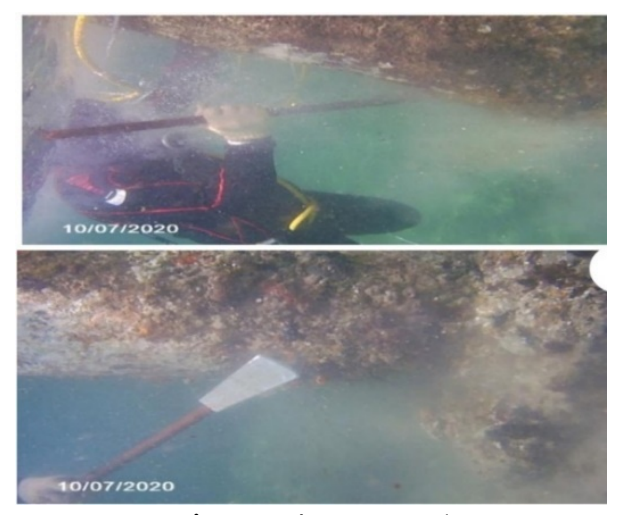

Figura 4: Etapa 1

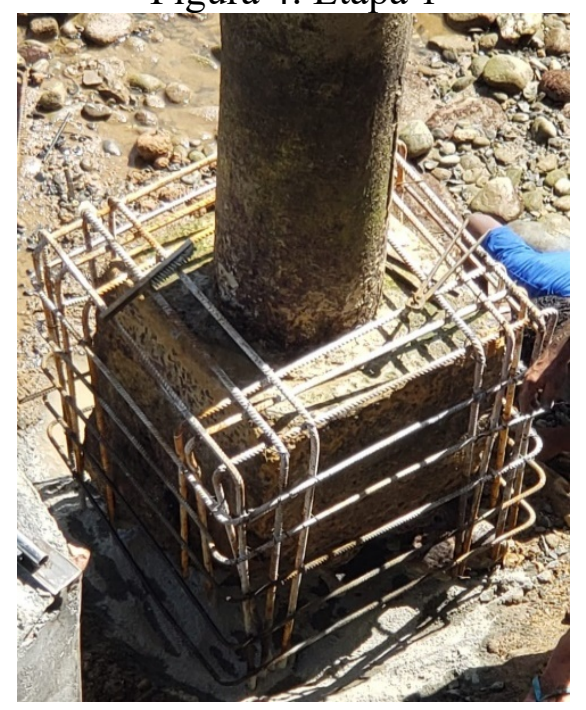

Figura 6: Etapa 3

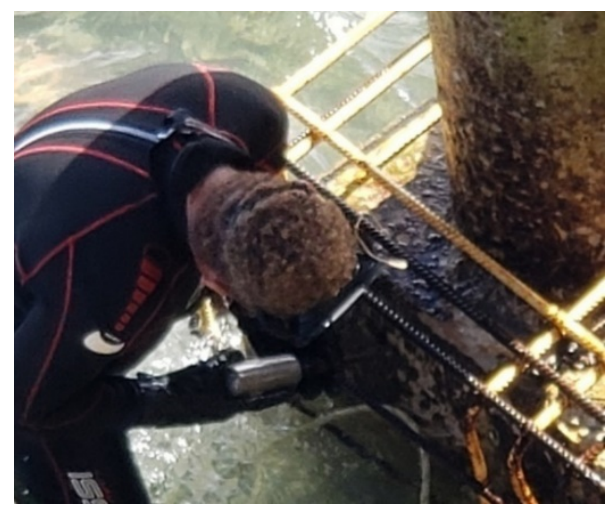

Figura 5 - Etapa 2

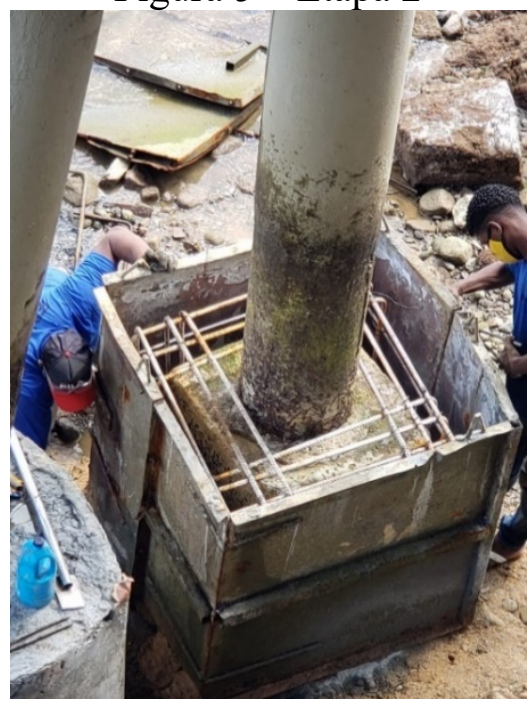

Figura 7: Etapa 4 


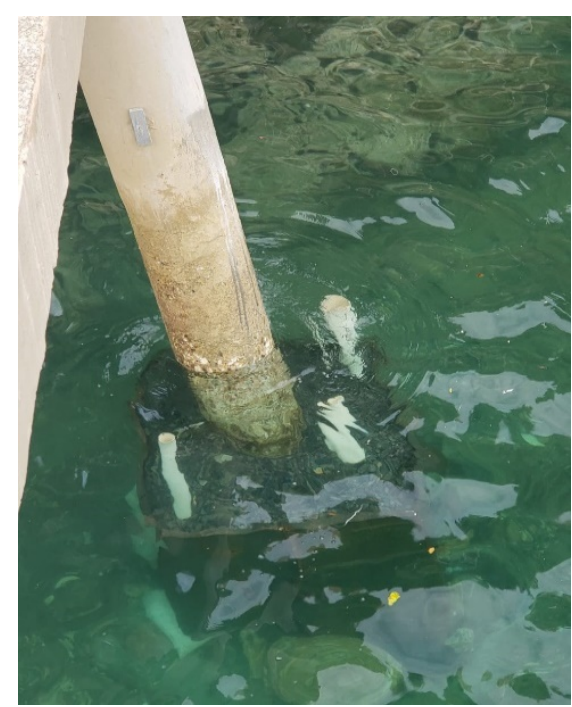

Figura 8: Etapa 5

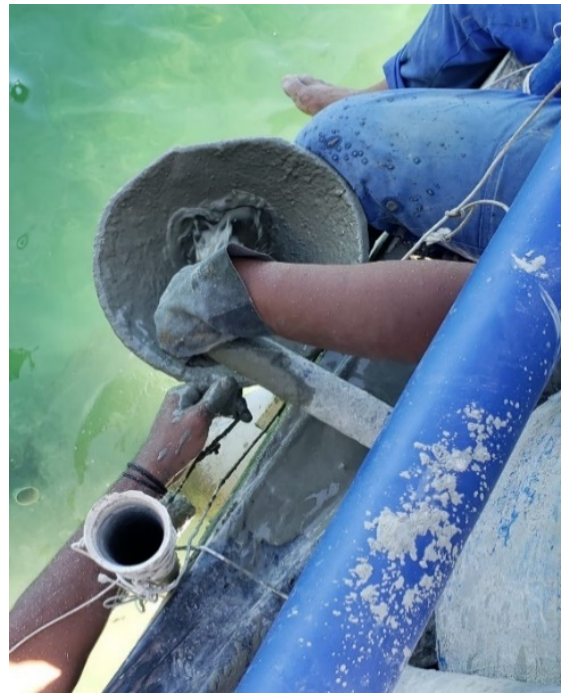

Figura 9 Etapa 6

\section{RESULTADOS}

Uma vez que a estrutura de concreto está em constante contato com a água do mar, a chance de ocorrer danos é muito. A chance de danos é reduzida, pela menor disponibilidade de oxigênio e atuação de agentes agressivos como o gás carbônico que promove carbonatação, Existe corrosão na ausência de oxigênio, é um processo diferenciado da corrosão usual, não é expansiva, mas consome o aço. Chama "corrosão anaeróbica", às vezes é até mais preocupante.

Porém, se a estrutura estiver localizada em um espaço onde o movimento da maré deixa a estrutura submersa por um período e em outros não, pode acontecer a aceleração do processo de corrosão. Com isso, a estrutura estará propensa a sofrer danos mais rapidamente.

Os resultados obtidos foram elementos totalmente recuperados, com aspecto bem-acabado, sem manifestações patológicas aparentes, conforme pode ser visto nas Figuras 10 a 17. 


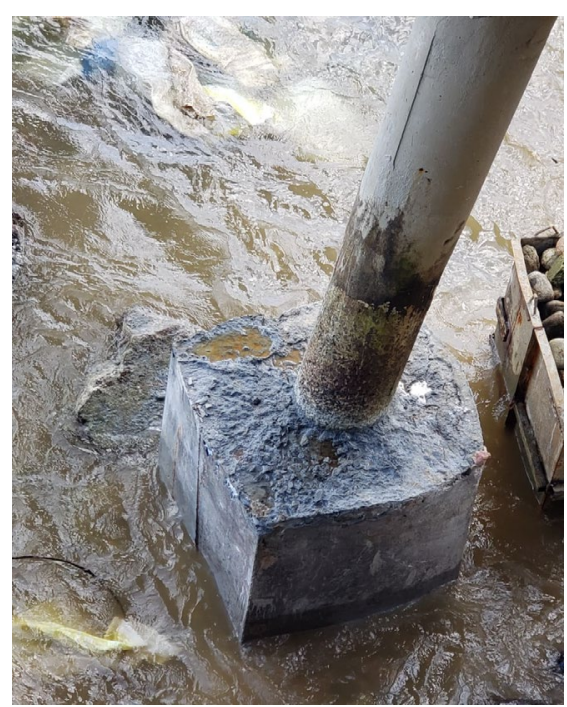

Figura 4: Aspecto final do bloco da ponte.

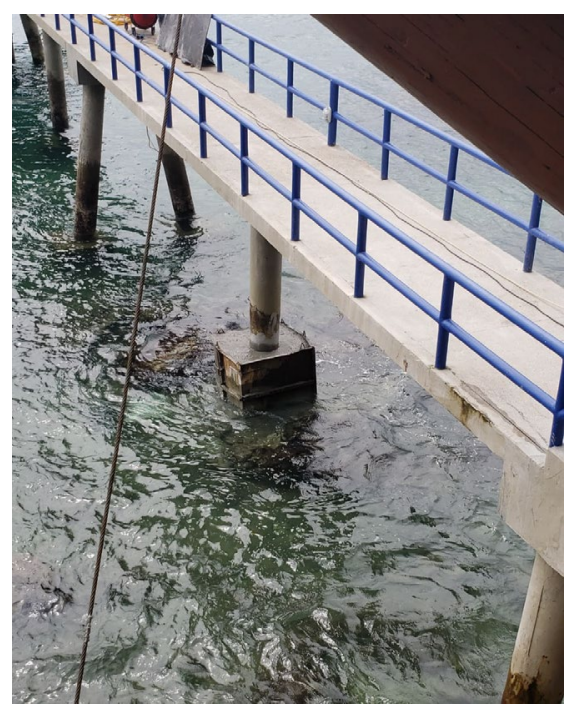

Figura 6: Aspecto final do bloco da ponte do píer.

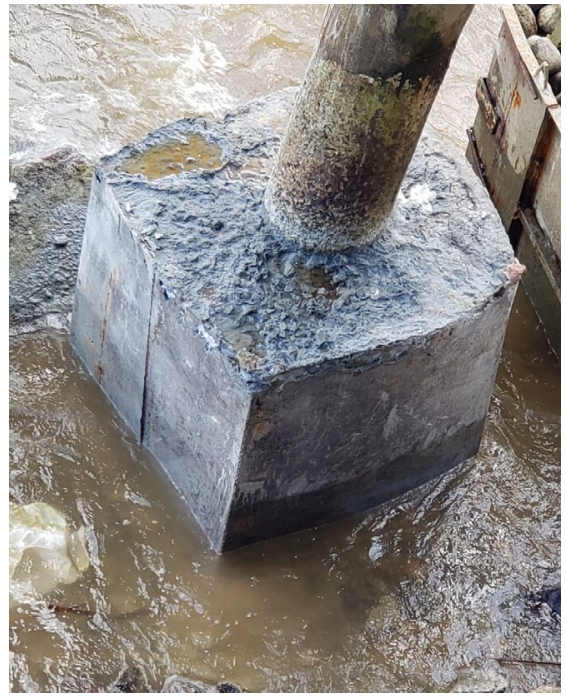

Figura 5:Detalhe da Figura 10.

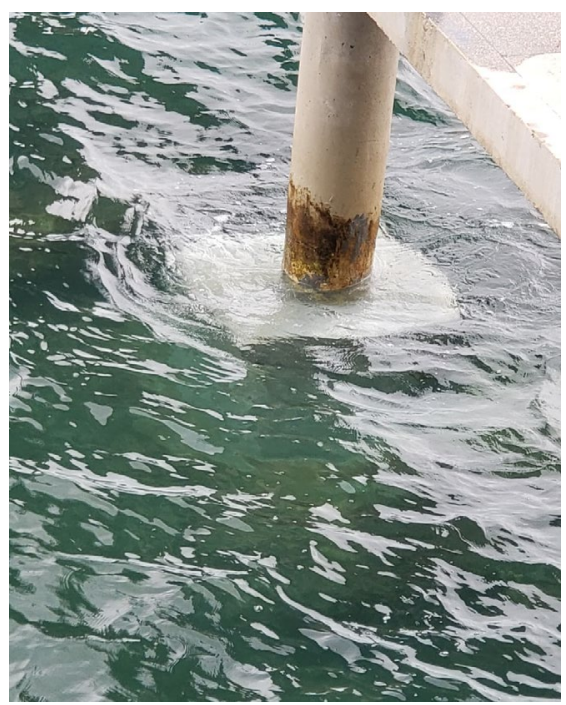

Figura 7: Detalhe da Figura 12. 


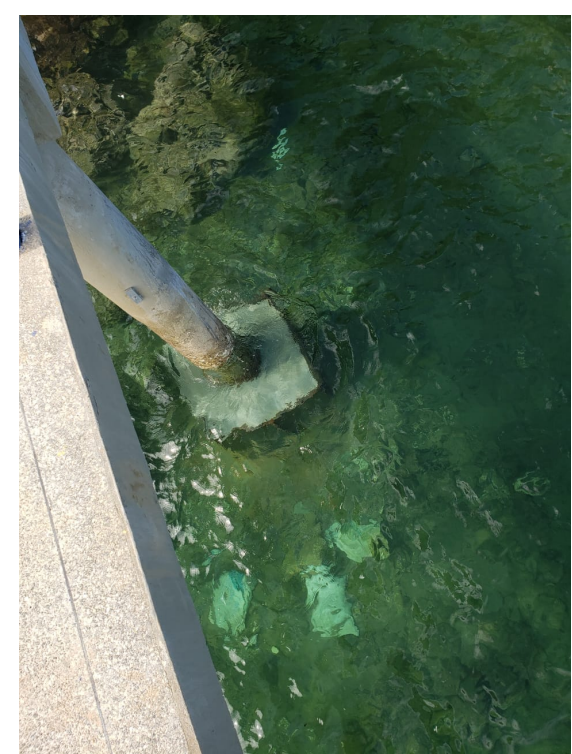

Figura 8 Aspecto final do bloco da ponte do Figura 9: Detalhe da Figura 14. píer.

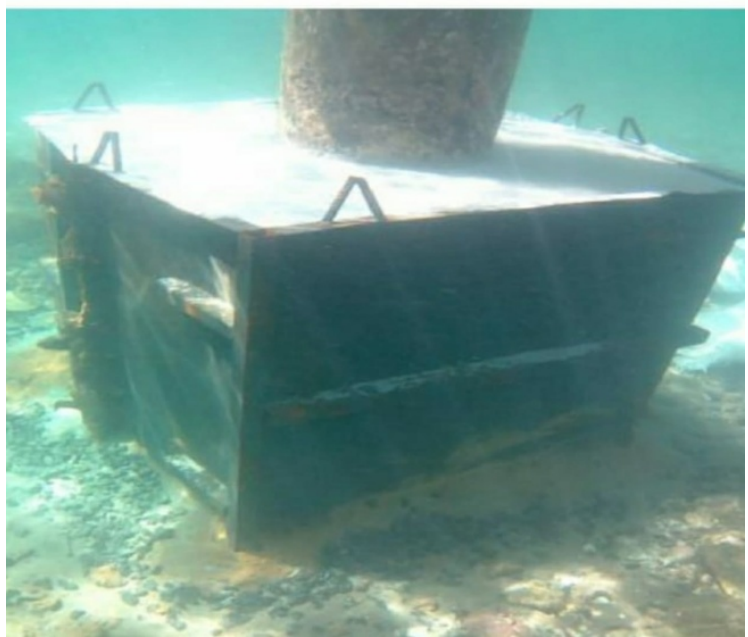

Figura 10 Aspecto final do bloco da ponte do píer.
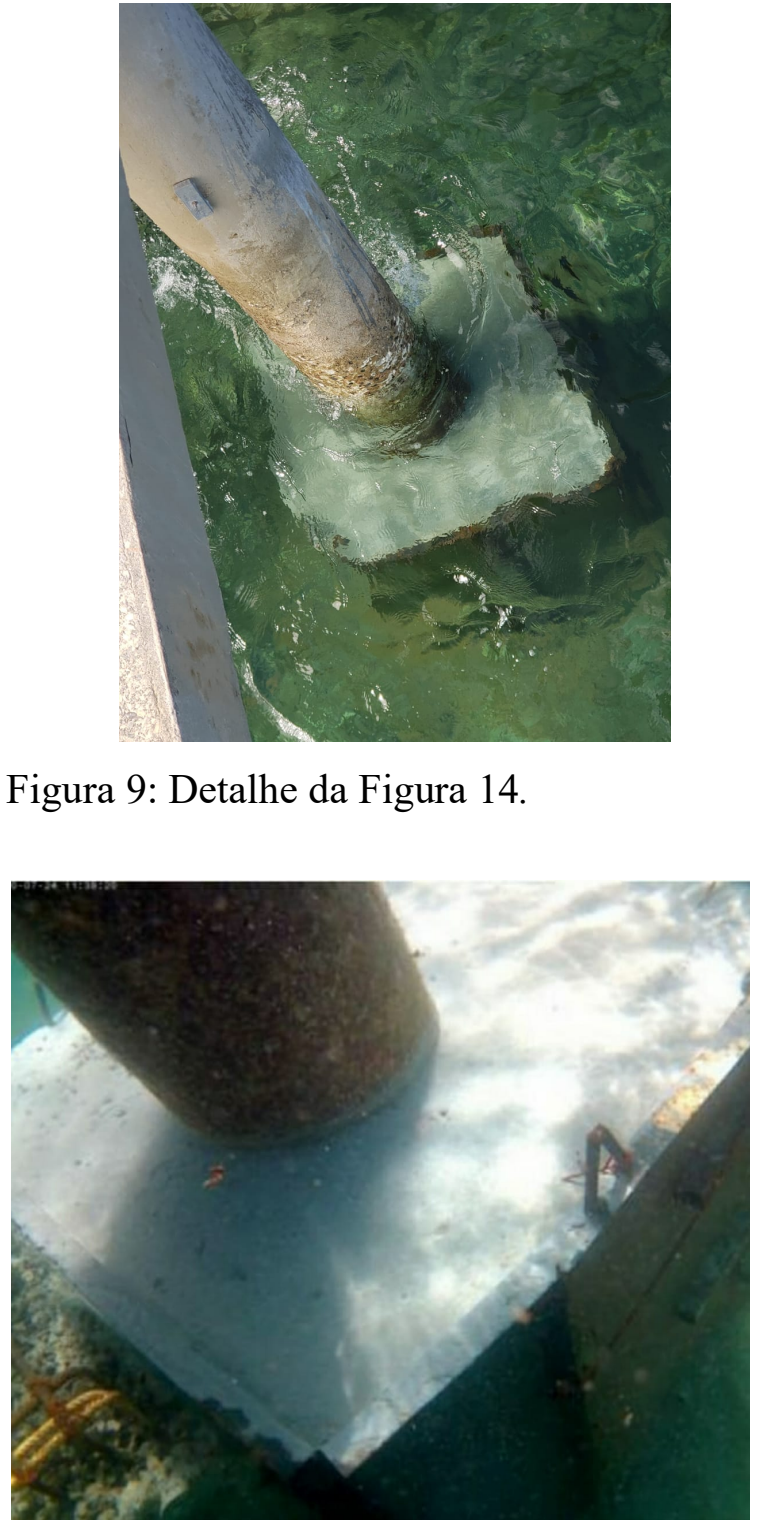

Figura 11: Detalhe da Figura 16.

\section{CONCLUSÃO}

Ao longo deste trabalho pôde-se observar a importância dos procedimentos de recuperação e reparo. As estruturas de concreto podem atingir sua vida útil esperada devido à falha na concepção, planejamento e execução do projeto, manutenção e uso correto etc. As estruturas subaquáticas apresentam nível de agressividade ambiental nível III ou IV dependendo da sua localização, pois oferecem o risco mais elevado de deterioração para as estruturas de concreto cujas propriedades são expostas e cuja durabilidade é comprometida.

Este estudo apresentou algumas técnicas de reparo importantes na recuperação subaquática. Para isso, executou-se como primeiro passo o processo da inspeção subaquática, e dentro dessa sequência, destacam-se alguns ensaios tecnológicos que apontam para uma metodologia de reparo. O estudo de caso surge como uma experiência de observação e aplicação de algumas técnicas de reparo de estrutura submersa. Neste procedimento de reparo, é necessário determinar com cuidado o tipo de concreto a ser escolhido, as atividades de limpeza até a concretagem, o que requer o 
acompanhamento do mergulhador. Também é preciso ter cuidado com o controle do tempo de injeção e lançamento do concreto submerso. Ao longo da recuperação, houve dificuldade para determinar um padrão de execução das atividades de recuperação, na medida em que cada profissional trabalha de uma maneira. É importante salientar que também são necessários mão de obra qualificada, equipamentos específicos e atenção ao tempo como um fator de extrema importância. Dependendo das condições climáticas, as obras subaquáticas podem sofrer vários tipos de problemas como atraso na execução relacionado à maré, ao vento, às ondas violentas etc. Além desse fator, que ocorre em qualquer intervenção, teve influência da maré? Era necessário esperar baixar pra instalar as fôrmas, etc.

\section{REFERÊNCIAS}

ABRAMS, M. S. (1971), Compressive strength of concrete at temperature to $1600{ }^{\circ} \mathrm{F}$ : SP 25 temperature and concrete. Detroit: American Concrete Institute.

ACI COMMITTEE 546 (1998), Guide to underwater repair of concrete. [S. I.]: American Concrete Institute.

Associação Brasileira de Normas Técnicas (2015). NBR 12655: Concreto de cimento Portland Preparo, controle, recebimento e aceitação.

GOMES, L. V. R. (2016) Estudo de métodos de ensaio e comportamento físico e mecânico de argamassas. Dissertação (Mestrado) - Curso de Pós-graduação em Engenharia Civil, Universidade Federal do Espírito Santo, Vitória.

HELENE, P. R. L (1992). Manual para reparo, reforço e proteção de estruturas de concreto. 2. ed. São Paulo: PINI p85.

LONG, M (2013). Etude des ouvrages maritimes et fluviaux renforcés par des matériaux composites. 2013. These (Docteur de l'université Spécialité Sciences pour l'ingénieur) - Université d'Artois, Arras, p 120.

MEHTA, P. K (1991). Concrete in the marine environment. Oxford: Elsevier Science Publishers.

NEVILLE, A. M (1997). Propriedades do concreto. 2. ed. São Paulo: Pini, p 85.

SOUZA, V.; RIPPER, T (2009). Patologia, recuperação e reforço de estruturas de concreto. São Paulo: PINI. 